\title{
A Química da Cortiça: ponto da situação
}

\author{
LUÍS MANUEL C. C. GIL*
}

É abordada a química da cortiça, nomeadamente a sua constituição, a partir da estrutura do tecido celular, fazendo-se uma descrição abreviada do estado dos conhecimentos respeitante a cada um dos grupos de constituintes e referindo-se a incidência industrial da cortiça como matéria-prima na obtenção de produtos químicos.

São também apresentadas as lacunas de conhecimento e as vias de estudo sobre este tema, acerca do qual os estudiosos não se têm debruçado tanto quanto seria de desejar, nomeadamente em Portugal, em que a cortiça possui uma importância determinante.

\section{INTRODUÇÃo}

0 estudo da constituição química da cortiça foi iniciado no século XVIII, aparecendo referências bibliográficas cadenciadas ao longo do tempo, até ao início da $2^{\mathrm{a}}$ Guerra Mundial, altura em que, dada a escassez de algumas matérias-primas, houve necessidade de implementar 0 estudo de produtos alternativos, entre os quais a cortiça.

Surgiu então um maior fluxo de informação relacionada com este material, sobretudo da autoria de investigadores americanos, franceses e espanhóis, aparecendo a partir da década de 50 também alguns trabalhos de investigadores portugueses, com maior frequência nos anos 80 .

Dado 0 interesse estratégico da cortiça no contexto nacional - e também a nível internacional, sendo de salientar que a NASA inclui este material numa lista de matérias-primas com interesse para aplicação em aeronáutica espacial e militar [1] - e verificando-se que 0 estudo da sua composição e aplicação de produtos químicos derivados não têm ocupado muito os químicos do nosso país, havendo ainda muito por estudar neste domínio, será importante averiguar 0 que actualmente se sabe, avaliando-se os temas controversos e os que ainda estão por explorar.

\section{CORTIÇA COMO MATERIAL}

A cortiça é um material com aplicações conhecidas desde a Antiguidade, sobretudo como artefacto flutuante $e$ como vedante, cujo mercado teve uma enorme expansão a partir do início deste século, face ao desenvolvimento dos diversos tipos de aglomerados.

Por definição [2], a cortiça é o parênquima suberoso originado pelo meristema súbero-felodérmico do sobreiro (Quercus suber, L.), constituindo o revestimento do seu tronco e ramos.

Macroscopicamente, é um material leve, elástico e praticamente impermeável a líquidos e gases, imputrescivel, deivido à pobreza em elementos albuminóides e à presença de taninos [3].

Trata-se de um tecido vegetal, constituido por células mortas, em camadas sucessivas (com valores médios entre 40 e 100 milhões por $\mathrm{cm}^{3}$ ), cujas membranas sofrem suberificação - deposição em camadas de compostos que Ihe conferem impermeabilização - e que contêm no seu interior uma mistura gasosa rica em azoto [4]

As células produzidas no Outono são em menor número, mais curtas e de paredes celulares mais espessas do que as chamadas células de Primavera, cuja diferenciação constitui as camadas anuais (anéis), que correspondem à cortiça produzida durante um ciclo vegetativo anual.

As células de cortiça típicas têm 0 formato de um prisma hexagonal, estando empilhadas lateralmente de modo que cada célula está em contacto com 14 células vizinhas, e com uma disposição segundo as diferentes direcções, de acordo com 0 que se pode observar na Figura 1.

Figura 1. Disposição das células de cortiça
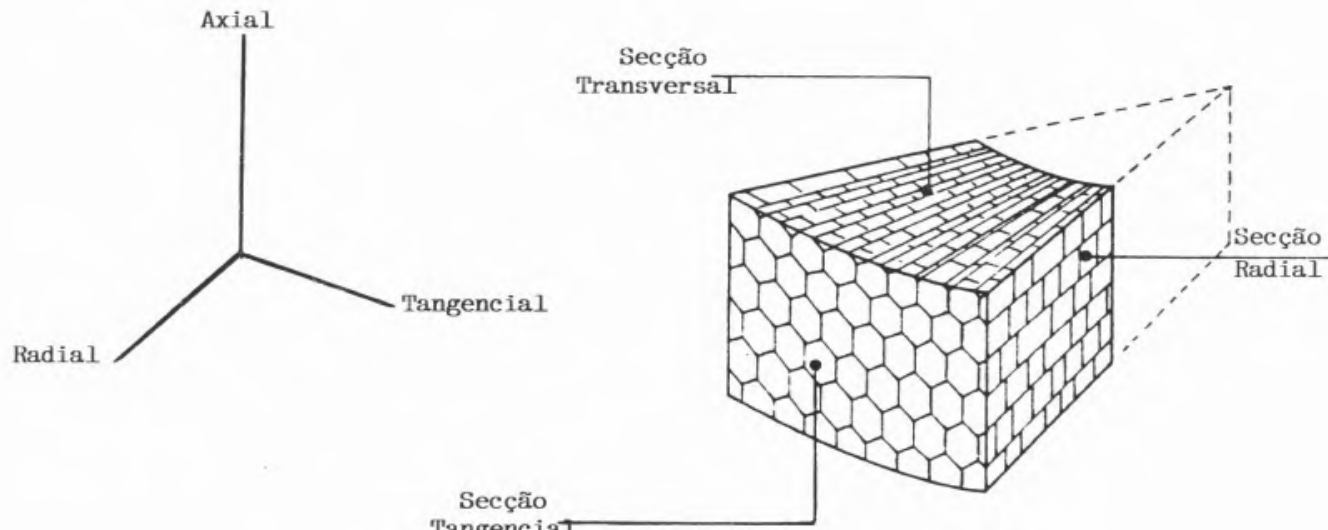
Estas células apresentam uma dimensão média de $20-25 \mu \mathrm{m}$ e a espessura das paredes celulares é de $1,5 \mu \mathrm{m}$.

As paredes celulares são constituídas por três camadas - uma lamela média e uma parede primária fina lenhificada, uma parede secundária formada por camadas alternadas de suberina $e$ ceras, e uma parede terciária de lenhina e celulose [5], como se pode ver na Figura 2. São as paredes primária e terciária que conferem a estrutura de suporte às células.

\section{COMPOSIÇÃO QUÍMICA DA CORTIÇA}

A cortiça engloba na sua composição vários tipos de compostos, que tradicionalmente são divididos em cinco grupos, apresentando os seguintes valores típicos [6]: Suberina (45\%); Ienhina (27\%); polissacáridos (12\%); ceróides (6\%); e taninos (6\%).

Estes grupos são assim considerados face ao conjunto de compostos que incluem e ao seu modo de obtenção/separação. Os valores médios indicados podem ter variâncias elevadas, dado a cortiça ser um material natural, cuja constituição é influenciada por diversos factores - tipo de solo, clima, condições vegetativas, idade da árvore, tipo de exploração florestal - e ainda
Figura 2. Estrutura da parede celular da cortiça

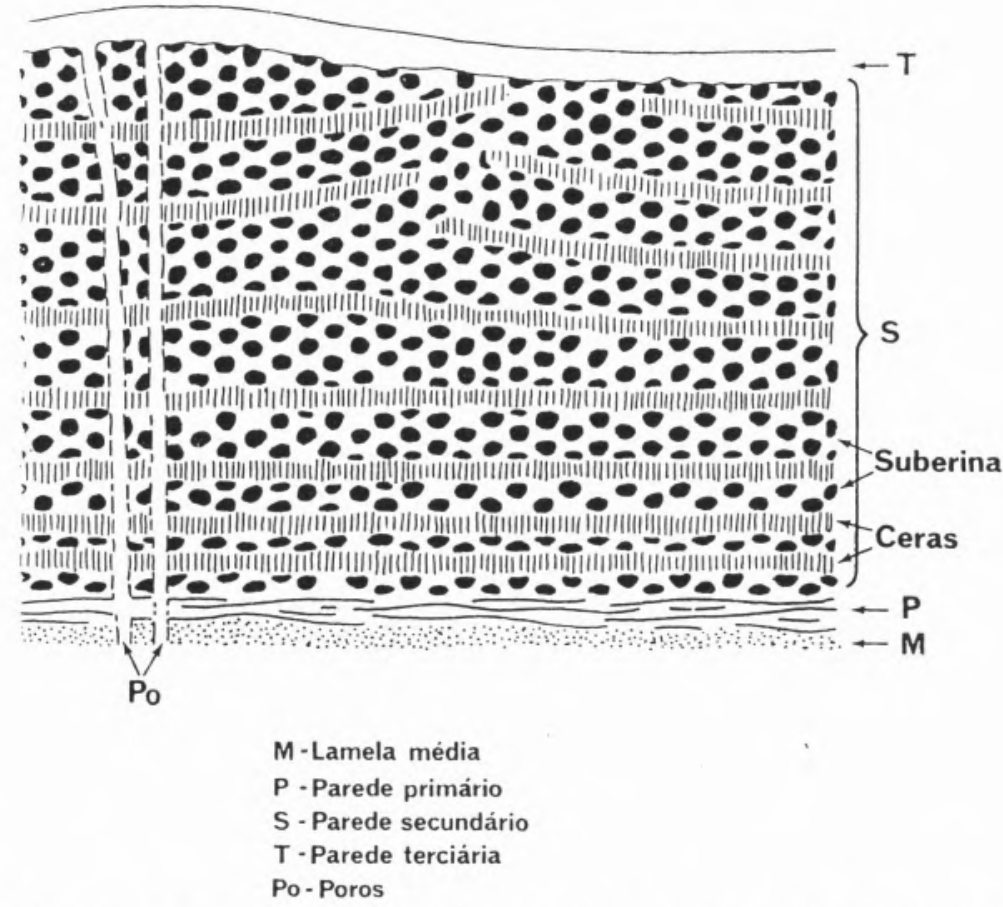

por poderem ser relativos a diferentes tipos de cortiça e métodos de análise.

A suberina é o componente maioritário da cortiça e tem sido um dos mais estudados. Existe nas paredes celulares, em camadas alternadas com substâncias ceróides.

É um polímero misto de monóme- ros aromáticos e alifáticos (poliéster), com uma estrutura complexa, e constituido por ácidos gordos de cadeia longa (18 a 30 átomos de carbono), cujas funções carboxilicas se encontram esterificadas por compostos fenólicos (ligações éster entrecruzadas) [7].

Um modelo proposto [8] é o apre-

Figura 3. Proposta de modelo para a estrutura da suberina [5]

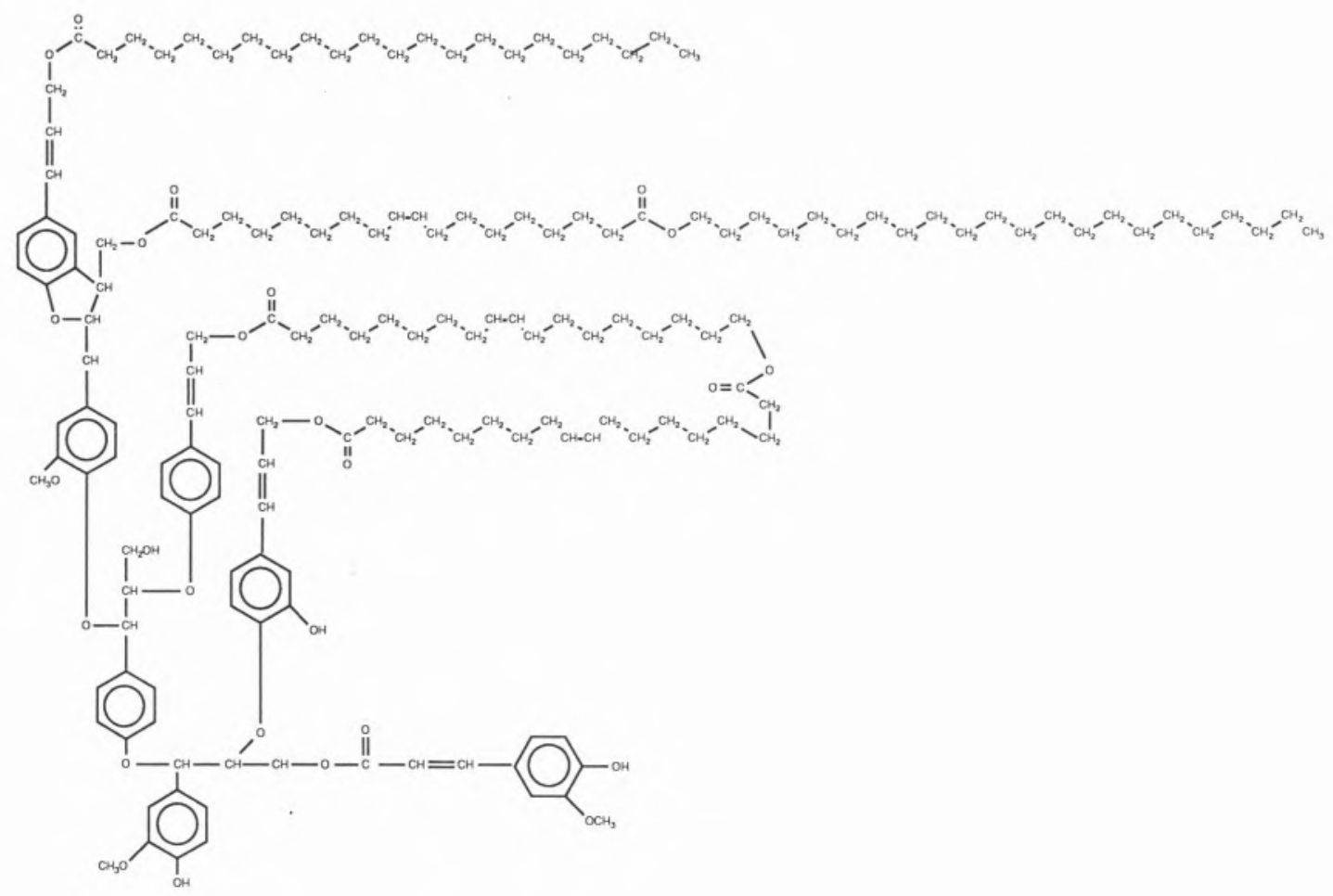




\section{artigos}

sentado na Figura 3.

Por despolimerização da suberina, obtêm-se hidroxiácidos alifáticos, ácidos gordos (mono e dicarboxílicos), alguns alcanóis e resíduos fenólicos. Verificou-se que os monómeros da suberina são maioritariamente constituídos pelos hidroxiácidos com 16 a 26 átomos, seguindo-se os ácidos dicarboxílicos e todos os outros (alcóois alifáticos e ácidos monocarboxílicos) [9], sendo os mais importantes, quantitativamente, os ácidos 22-hidroxidocosanóico, 9,10-dihidroxioctadecanodióico, 9,10,18-trihidroxioctadecanóico e docosanodióico. Quanto aos resíduos fenólicos, é escassa a informação.

Estes compostos, por serem multifuncionais, apresentam interesse em reacções de polimerização inter e intramoleculares, quer para o conjunto de componentes [10], quer para alguns componentes em particular [11].

Verificou-se ainda que há diferenças no teor de suberina em diferentes qualidades de cortiça, com uma diminuição deste teor para a cortiça de inferior qualidade [5].

A lenhina é também um polímero de estrutura entrecruzada, parcialmente aromática, constituído por alcoóis derivados do 1-fenilpropano [12]. Na cortiça, a lenhina é habitualmente obtida como resíduo, após extracção dos ceróides e taninos com solventes, despolimerização da suberina e hidrólise dos polissacáridos.

A macromolécula da lenhina, tem elevado peso molecular, sendo o componente que confere rigidez à parede celular. 0 modelo da matriz polimérica da lenhina da cortiça é o mesmo da madeira.

Dado que se trata de um polímero com uma estrutura amorfa, irregular e reticulada, ao contrário dos polissacáridos, existem valiosas aplicações possiveis para os seus fragmentos menores [13].

Os polissacáridos da cortiça, são constituídos por dois tipos de polímeros; a celulose (homopolímero) e as hemiceluloses (heteropolimeros).

Estes compostos são também polímeros de elevado peso molecular, sendo a celulose constituída por monómeros de $\beta$-D-glucopiranose, interligados por ligações glicosídicas [12].

As hemiceluloses (hexoses e pentoses), estão associadas à celulose e à lenhina na parede das células [12], sendo facilmente hidrolisadas por ácidos, originando-se os seus constituintes monoméricos. São também solúveis em água e

Figura 4. Fórmulas de estrutura dos principais triterpenóides da cortiça

\section{Cerina}<smiles>CC1C(=O)C(O)CC2C1(C)CCC1C2(C)CCC2(C)C3CC(C)(C)CCC3(C)CCC12C</smiles>

Friedelina<smiles>CC1C(=O)CCC2C1(C)CCC1C2(C)CCC2(C)C3CC(C)(C)CCC3(C)CCC12C</smiles>

em soluções fracamente alcalinas.

Os polissacáridos, em associação com a lenhina, são os responsáveis pela estrutura de suporte das paredes das células de cortiça.

A fracção ceróide da cortiça é constituída por alcanos (de 16 a 34 átomos de carbono), alcanóis ( 29 a 36 átomos de carbono) e triterpenóides (maioritários) $[5,7]$.

Estes produtos são usualmente obtidos directamente da cortiça, por extracção com solventes orgânicos e posteriores operações de separação e purificação, o que demonstra que se encontram duma forma não combinada nas paredes das células [6,14], parecendo contribuir, conjuntamente com a suberina, para uma certa impermeabilização das mesmas.

Entre os triterpenóides, dado o seu quantitativo, são de destacar a friedelan3 -ona que corresponde a cerca de $2 \%$ em peso da cortiça e a 2-hidroxifriedeIen-3-ona [6,7], cuja estrutura é apresentada na Figura 4.

Foram também isolados outros derivados de esqueleto triterpénico $[7,15]$; estes compostos apresentam pesos moleculares entre 400 e 600 $\mathrm{g} / \mathrm{mole}$, com pontos de fusão entre $250^{\circ} \mathrm{C}$ e $320^{\circ} \mathrm{C}[16,17]$.

Verificou-se haver um maior teor de ceróides na cortiça virgem, quando comparada com a cortiça de reprodução. Há conhecimento de tentativas de aplicação dos ceróides em bruto, como ceras de utilização comum [10] e de alguns dos seus componentes em utilização de alto valor acrescentado [18].

Na chamada fracção taninosa, os taninos, obtidos da cortiça por extracção com água, são os componentes existentes em maior percentagem [19].

Estes, são compostos fenólicos que aparecem numa forma polimerizada, com pesos moleculares habitualmente compreendidos entre 500 e 3000 $\mathrm{g} /$ mole, sendo usualmente divididos em dois grupos $[7,20]$ : taninos hidrolisáveis e taninos condensados.

Os primeiros, também designados pirogálhicos, são constituídos por ésteres do ácido 3,4,5,-trihidroxibenzóico e 
da glucose e por outros compostos similares que, por hidrólise com água, dão origem a estes produtos.

Os taninos condensados (ou catéquicos), são formados por policondesação de monómeros do tipo flavonóide, constituindo polímeros de catequinas (flavanóis) e leucoantocianidinas (flavanodióis).

Nesta fracção de componentes químicos há que referir ainda as substâncias fenólicas simples, como por exemplo o o-dihidroxibenzeno [20].

Os taninos possuem numerosas aplicações do ponto de vista industrial [21,22] e mesmo em medicina [23].

Foram também isolados da cortiça alguns esteróides, obtidos dos residuos de material suberoso, após extracção com solventes e saponificação [24], tendo sido referenciado, por exemplo, 0 24R-estigmaest-5-en-3 $\beta$-ol.

A composição mineral da cortiça, é reflectida globalmente no seu teor de cinzas, com valor entre $1 \%$ e $3 \%$ em peso [25].

Através da análise de elementos existentes, verificou-se ser o cálcio o elemento mais abundante, existindo ainda uma quantidade proporcionalmente importante, constituida por potássio, fósforo e magnésio $[5,26]$.

Os teores de elementos minerais da cortiça, sobretudo o cálcio e 0 magnésio, são baixos quando comparados com outros referentes à casca de árvores da mesma familia, o que poderá estar relacionado com a baixa fertilidade dos solos onde o sobreiro floresce [27].

Um trabalho de revisão mais completo sobre a composição química da cortiça, reflectindo uma pesquisa bibliográfica exaustiva sobre este tema foi já efectuado [28], havendo conhecimento de três trabalhos posteriores [29-31]

\section{PROCESSOS DE OBTENÇÃO E APLICAÇÕES DOS COMPONENTES QUÍMICOS DA CORTIÇA}

Em 1949, iniciou-se a produção industrial em França, de produtos químicos a partir da cortiça, baseada nas patentes de dois professores franceses, para obtenção de uma mistura de ácidos gordos, por saponificação directa de granulado de cortiça, com uma solução alcalina [32]. Tem-se conhecimento de terem sido montadas a fábrica FRANSUBER e posteriormente a QUICOR, respectivamente em França e Portugal, tendo no caso português a fábrica sido encerrada ao fim de poucos anos (extraía ceras e ácidos gordos da cortiça para fins diversos).

Estes processos [32,33] permitiam a obtenção da mistura de ácidos gordos da cortiça, mas como havia interesse na obtenção de diversos monómeros isolados, foram desenvolvidos processos baseados na diferente solubilidade dos sais compostos. Um destes processos foi também objecto de patente no nosso pais [34] e há conhecimento de um outro patenteado nos Estados Unidos [35].

As primeiras referências sobre as aplicações dos monómeros da suberina, individualmente ou em grupo, relacionam-se com a obtenção de materiais poliméricos e com a utilização de um dos monómeros na sintese de produtos para perfumaria $[10,11]$. Esta sintese, dá origem a uma cetona cíclica, com aroma a almíscar [14]. São descritas aplicações de misturas de ácidos gordos em emulsão na estabilização da borracha $[3,10]$ e para conferir propriedades de aderência a vernizes [32,36].

A utilização da polimerização dos monómeros da suberina, após pré-despolimerização, como auxiliar de aglomeração de partículas de cortiça, foi um processo também já patenteado $[29,37]$ em Portugal.

No caso da lenhina, pode-se, por exemplo, obter a vanilina (fragância e sabor) a partir dos seus framentos [13]. São também conhecidos métodos para a produçẫo de polímeros de diferentes tipos, a partir da lenhina e dos seus produtos de degradação de baixo peso molecular [38]. Há também outras utilizações possiveis: como fonte de energia e no fabrico de colas do tipo fenol-formaldeído [38].

Nos finais da década de 40 surgiram também as aplicações industriais para os ceróides da cortiça, uma vez que, dado o seu elevado ponto de fusão, estas ceras permitem substituir com vantagem as ceras de utilização comum, con fins variados, como sejam o revestimento de frutas, aplicações em tintas e vernizes, ceras e graxas industriais e outras [39], sobretudo para aplicações alta temperatura.

Do ponto de vista industrial, refirase, no entanto, a obtenção mais fácil e vantajosa dos ceróides da cortiça, a partir de um resíduo da indústria corticeira, os condensados do vapor de cozimento do aglomerado negro, que constituem só por si um extracto em bruto da cortiça. É assim possivel obter, por exemplo, a friedelan-3-ona, através de operações fáceis de extracção, separação e purificação, cuja aplicação em formulações para cura de certos tipos de cancro, inflamações, úlceras e desinterias foi já estudada [18]; conhecem-se também as suas propriedades anti-fágicas para certos insectos $[18,30]$.

Entre as utilizações industriais dos taninos referem-se a curtição de peles, a protecção de redes de pesca, aplicação em tintas e inibidores de fungos $[21,22]$. São referidas ainda aplicações em medicamentos para doenças do coração [23]. Além deste tipo de utilizações, os taninos condensados, podem ser usados como matéria-prima na síntese de resinas do tipo fenol-formaldeído [40].

\section{CONCLUSÕES}

Como se pode depreender dos trabalhos publicados sobre a química da cortiça, a evolução dos conhecimentos foi acompanhando os avanços da quimica laboratorial. As novas técnicas analíticas que foram surgindo permitiram novas aproximações e 0 esclarecimento de algumas questões ainda pendentes.

Apesar de tudo isto, pode-se afirmar que há ainda muito por estudar neste campo, quer no que diz respeito à identificação de novos compostos, principalmente dos grupos de componentes menos estudados, nomeadamente os taninos e a lenhina, quer partindo posteriormente para estudos de aplicação destes, nos mais variados domínios.

Mais especificamente, no caso de suberina parece evidente que foram esquecidos os compostos aromáticos, cuja quantificação e identificação poderiam contribuir para o esclarecimento da controvérsia ainda existente, relativamente à sua estrutura. Para além de estudos com interesse sobre novos tipos de polímeros, baseados nos monómeros da suberina, seria ainda importante aprofundar os estudos da sua ciclização e aplicações.

Por outro lado, poderia ainda ser estudada a reactividade e actividade (nomeadamente biológica) dos compostos obtidos da cortiça ou dos seus derivados, no seguimento de alguns dos estudos já efectuados.

Estes estudos para novas aplicações, deveriam ter como objectivo prioritário a obtenção de produtos de alto valor acresentado, e de um modo integrado que permita a utilização de todas as fracções constituintes, valorizando o papel da 
cortiça como matéria-prima de base.

Finalmente, e dado a cortiça ser um produto natural, cuja composição varia devido a inúmeros factores, seria muito interessante relacionar a sua composição química, através da quantificação individual ou relativa de grupos de componentes, com o comportamento e características macroscópicas da cortiça, permitindo quantificar a "qualidade" do material, o que até aqui tem sido realizado de modo muito subjectivo.

\section{REFERÊNCIAS}

1. J. Cobra, "As questões da qualidade face ao desenvolvimento de estratégias empresariais", Intervenção no Seminário Internacional de Cortiça, Porto, Novembro 1991.

2. Norma Portuguesa NP-273-Cortiça. Terminologia-CT-16, IPQ, Lisboa, 1970. 3. M.J. Gonçalves, "Química da cortiça Contribuição para o seu conhecimento". Boletim do IPF-Cortiça, 191 (1954) 303; 193 (1954) 7.

4. J.V. Natividade, Subericultura, Porto, Ministério da Economia - Direcção Florestais e Agrícolas, 1950.

5. M.M. Caldas; J.M.L. Ferreira; M.A. Borges, "Abordagem sobre a caracterização química da cortiça nas várias etapas do processamento industrial", Boletim do IPF - Cortiça, 560 (1985), 549.

6. A. Guillemonat, "Progrés récent das l'étude de la constitution chimique du liège". Bull. Fac. Sci. Marseille, (1960), 45.

7. H. Pereira, "Constituição química da cortiça - Estado actual dos conhecimentos", Boletim IPF - Cortiça, 483, (1979), 259.

8. P.E. Kollattukudy, "Lipid polymers and asociated phenols", in F.A. Loewus, and V.C. Runeckles, The Structure, Biosynthesis and Degradation of Wood, Plenum,1977, 7-227.

9. P.J. Holloway, "Composition of suberin from the corks of Quercus suber and Betula pendula roth". Chem. Phys. Lipids, 9 (2) (1972), 158.

10. J. D'A. Martinie, "Uma nova utilizaÇão da cortiça", Boletim JNC, 140 (1950) 241.

11. J.F. Yanes, S.G.B. Ozores, "Polimeros obtenidos a partir de los ácidos del corcho". Rev. Plásticos Modernos, 159 (1969) 691.
12. J.F. Sian, Transport Process in Wood, Springer Verlag, Berlim (1984) 63-70.

13. J.S. Carvalho, J. S., "Algumas reflexões sobre a investigação química da cortiça", Boletim JNC, 287-288 (1962) 219-247.

14. I. Ribas-Marques, "Étude sur la constitution chimique du liège". Chimie \& Industrie, 68 (1952) 333.

15. I. Ribas-Marques, J. FernandezSalgado, "Quimica del corcho-XXIII. Investigaciones sobre los triterpenoides". Boletim IPF - Cortiça, 436 (1975) 35.

16. N.L. Drake, R.P. Jacobsen, "Cerin and Friedelin. I. Their Molecular Weights and Empirical Formulas". J. Am. Chem. Soc., 57 (1935) 1570.

17. Y. Chrétien-Béssière, L. Duhamel, Sur la présence de bétuline dans la liège". Mem. Soc. Chimique, Franç, (1962) 228.

18. R.F. Chandler, S.N. Hooper, "Friedelin and associated triterpenoids". Phytochemistry, 18 (1979) 711.

19. H. Pereira, "Doseamento dos taninos da cortiça de Quercus suber L.", Boletim IPF-Cortiça, 550 (1984) 244.

20. J. Soares, Taninos na cortiça. Laboratório de Estudo e Ensaio da Cortiça, Separata, Instituto dos Produtos Florestais, Lisboa, 1974.

21. J. Doat, "Les tanins dans les bois tropicaux". Bois et Forêts des Tropiques, 182 (1978) 37.

22. F. O'Flaherty, Chemistry and Technology of Leather. Vol. 4, Reinhold, 1965, 98-160.

23. R. Ikan, Natural Products $-A$ Laboratory Guide. Tel Aviv, Israel UP, 1969, 174-176.

24. J. Fernandez-Salgado, I. RibasMarques, "Química del corcho. XXI. Identificacion de $\beta$-sitosterol y campesterol". Acta Científica Compostelana. IX (1972) 139.

25. V. Marques, F. Mata, H. Pereira, "Composição mineral dos desperdícios de cortiça proveniente da indústria de granulados". Boletim IPF-Cortiça, $\mathbf{5 7 4}$ (1986) 233.

26. F. Mata, V. Marques, H. Pereira, "Influência da granulometria na determinação de elementos minerais na cortiça". Boletim IPF-Cortiça, 569, (1986), 68.

27, A.M. Rodrigues, "Química da cortiça-Contribuição para o seu estudo". Boletim IPF-Cortiça, 583 (1987) 23.

28. L. Gil, Cortiça. Tecnologia de Processamento e Constituição Química.
DTIQ/LNETI, № 3, 1988.

29. L. Gil, Fabrico de Aglomerados de Pó de Cortiça com Pré-Despolimerização da Suberina. Dissertação de Mestrado em Química Orgânica Tecnológica, UNL/DTIQ, 1988.

30. C. Moiteiro, M.R. Tavares, M.J.M. Curto, Produtos químicos obtidos a partir dos condensados do aglomerado negro de cortiça - Comunicação no $11^{\circ}$ Encontro Anual da SPQ, LNEC, Lisboa, 1988.

31. M.L. Mata, Identificação dos Constituintes Químicos do Pó de Cortiça e Sua Valorização por Hemisíntese. Dissertação de Mestrado em Química Orgânica Tecnológica, UNL/DTIQ, 1991.

32. A. Dugelay, "A química da cortiça. Primeiros resultados - Perspectivas futuras". Boletim JNC, 225 e 226 (1957) 257, 293.

33. Patente Portuguesa № 28599 (1951) - Processo para extrair ácidos orgânicos da cortiça sob a forma de ésteres, e produtos obtidos (A. Guillemonat).

34. Patente Portuguesa № 27590 (1959) - Processo de separação dos ácidos gordos da cortiça em várias fracções e preparação de produtos derivados, alguns no estado puro - (A. Guillemonat).

35. Patente Americana № 2872464 (1959) - Obtaining cork acids - Z.R. Brown; B. Rosen.

36. B. Mesquita, "Química da Cortiça". Boletim JNC, (1953) 310.

37. Patente Portuguesa № 88239 (1990) - Processo para a produção de aglomerados do pó da cortiça sem adição de colas, mediante pré-despolimerização da suberina e posterior polimerização por prensagem e aquecimento (L. Gil).

38. J.J. Lindberg; V.A. Era; T.P., Jahiainen, "Lignin as raw material for synthetic polymers". Applied Polymer Symposium, 28 (1975) 269.

39. A. Guillemonat, "Le liège, matiére premiére d'une industrie chimique". Revue du Bois et de ses Applications, 4(1) (1949) 4-6.

40. H. Pereira; V. Prata, "Utiliza-ção de extractos taninosos da cortiça como fonte fenólica no fabrico de resinas". Boletim IPF-Cortiça, 511 (1981) 119.

* UTIMC/INETI Estrada das Palmeiras, 2745 Queluz de Baixo 